\title{
Chemometric Approaches in Calibration Experiments of Trilinolenoylglycerol by Liquid Chromatography Ion-Trap Mass Spectrometry
}

\author{
Pedro Araujo, Thu-Thao Nguyen, and Livar Frøyland \\ Seafood and Health Research Group, National Institute of Nutrition and Seafood Research, Bergen, Norway
}

The article presents a comprehensive account of the application of chemometric approaches to determine the factors that influence the tri- $\alpha$-linolenoylglycerol (TALG) ammoniated adduct signal $\mathrm{m} / \mathrm{z} 890.6$ in an ion-trap mass spectrometer coupled to a liquid chromatograph and the estimation of different sources of errors involved in TALG calibration experiments. It was found that by using experimental design, the influence of the nebulizer pressure on the analytical signal is less pronounced than the influence of the drying gas flow and the chromatographic flow rate. The results revealed that without using tandem mass or atmospheric pressure chemical ionization, it is possible to fragment the TALG backbone and obtain the free $\alpha$-linolenic acid by varying the drying gas flow and using an electrospray interface. The error decomposition approach revealed that the preparation error was 26 times higher than the instrumental error. (J Am Soc Mass Spectrom 2005, 16, 388-396) (c) 2005 American Society for Mass Spectrometry

\begin{abstract}
A $\mathrm{s}$ an essential polyunsaturated fatty acid, $\alpha$-linoleic acid (ALA, 18:3n-3) is not synthesized de novo in animals, but must be provided in their diets in the form of triacylglycerol [1]. The development of analytical methods in the analysis and quantification of ALA and more general triacylglycerols (TAG) is of considerable importance $[2,3]$ in view of their involvement in many vital biochemical processes and their association with the alleviation of a wide variety of diseases [4,5]. Quantification of TAG using coupled techniques such as LCMS depends mainly on two aspects, the sample preparation technique and the instrumental condition settings. Well-established protocols and books [6-8] have been devoted to the former and nowadays many research laboratories around the world invest time and resources to investigate new, rapid, and simpler techniques. Works regarding the latter aspect are not widespread in the literature, perhaps because variation of the instrumental conditions can cause drastic alterations to the results obtained with a tested and optimized method [9]. Continuity of results within long periods of time (years) is of paramount importance in clinical studies [10], impairing in some degree the interest in the exploration of new or existing methodologies aiming at optimizing the set-
\end{abstract}

Published online February 4, 2005

Address reprint requests to Dr. P. Araujo, Seafood and Health Research Group, National Institute of Nutrition and Seafood Research (NIFES), P.O. Box 2029 Nordnes, N-5817 Bergen, Norway. E-mail: pedro.araujo@nifes.no ting of the LCMS instrumental conditions used in the quantitative analysis of TAG. Superb LCMS instruments equipped with automatic optimization devices could be another reason for the limited number of publications on this field. It has been reported that the sole chromatographic system is influenced by more than 50 factors [11], hence the complexity of chromatography coupled to mass spectrometry overwhelms even the most sophisticated software intended for automatic optimization and method development. The classic one-at-the-time methodology for optimization has been widely used in TAG quantification studies. One of the drawbacks of this method is that it is a tedious procedure and the true optimum can be missed if there are important interactions between the factors. The optimization of a LCMS method is prone to difficulties resulting from the inherent high number of instrumental factors involved and their interactions. The determination of the local response surface and exploitation of the local factor dependence is essential. The discovery and application of methods to that effect are extremely important. This study was undertaken, first to estimate the optimal combination of liquid chromatography-ion-trap-mass spectrometry (LCITMS) experimental variables, specifically nebulizer gas pressure, drying gas flow, and chromatographic flow rate involved in the quantitative determination of tri- $\alpha$-linolenoylglycerol (TALG) by using the response surface methodology, in particular a Doehlert matrix [12]; second, to study under optimal LCITMS 
condition settings, the different sources of errors implicated in TALG quantification experiments such as dilution, instrumental and lack-of-fit errors, and third, to determine quantitatively the TALG concentration in synthetic formulations.

\section{Materials and Methods}

\section{Samples}

Primary stock solutions of the standards tri- $\alpha$ linolenoylglycerol (TALG), 1,3,-di- $\alpha$-linolenoylglycerol (DAG), 1,-mono- $\alpha$-linolenoylglycerol (MAG), $\alpha$-linolenic acid (FFA) and 3-sn-phosphatidylethanolamine (PE) from bovine brain (Sigma-Aldrich, Bergen, Norway) were prepared in chloroform. TALG working solutions were prepared in chloroform by appropriate dilutions at $10,20,30,40$, and $50 \mu \mathrm{g} / \mathrm{ml}$. Mixtures of the MAG, DAG, FFA, and PE were prepared in chloroform and spiked with different concentrations of TALG to produce the calibration curve points equivalent to 10,20 , 30, 40, and $50 \mu \mathrm{g} / \mathrm{ml}$.

\section{Liquid Chromatography Ion-Trap Mass Spectrometry}

The LCITMS used in this study was an Agilent 1100 series LC/MSD trap, SL model with an electrospray interface (ESI), a quaternary pump, degasser, autosampler, thermostatted column compartment and variablewavelength UV detector. The column used a Zorbax Eclipse-C $_{8}$ RP $150 \times 4.6 \mathrm{~mm}, 5 \mu \mathrm{m}$ (Agilent Technologies, Palo Alto, CA) was kept in the column compartment at $40{ }^{\circ} \mathrm{C}$. The solvent system operated in isocratic mode was 2-propanol/water (vol/vol 90/10) with ammonium acetate added at a concentration of $10 \mathrm{mM}$ and UV detection at $254 \mathrm{~nm}$. TALG dissolved in chloroform was infused into the ESI source with a KD Scientific syringe pump at a flow rate of $10 \mu \mathrm{l} / \mathrm{min}$. Nitrogen was used as nebulizing and drying gas at $350{ }^{\circ} \mathrm{C}$. The ESI source was operated in positive ion mode and the ion optics responsible for getting the ions in the ion-trap such as capillary exit, skimmer, lens and octapoles voltages were controlled by using the Smart View option. The $m / z$ range scanned in the MS measurement was 100-1000 and resolution of 13,000 m/z/s (FWHM/ $m / z=0.6-0.7)$. Complete system control, data acquisition and processing were done using the ChemStation for LC/MSD version 4.2 from Agilent.

\section{Chemometric Approaches}

Uniform shell design. The effect of the nebulizer pressure $\left(z_{1}\right)$ and the drying gas flow rate $\left(z_{2}\right)$ variables from the ion-trap along with the chromatographic flow rate $\left(z_{3}\right)$ on the characteristic signal of TALG ammoniated ion $\left[\mathrm{M}+\mathrm{NH}_{4}\right]^{+}$at $\mathrm{m} / \mathrm{z} 890.6$ was studied by using a uniform shell design developed by Doehlert [12]. Figure 1 described the generation of this uniform shell design for two and three factors whose main characteristics are:

- The design displays an equally spaced distribution of experimental points circumscribed to a sphere of radius 1 ; in this way the variance of the estimated response is the same at all points on the sphere centerd at the origin.

- The number of experiments suggested by this design is calculated according to the general expression $Z^{2}+$ $Z+1$ where $Z$ represents the number of variables to be investigated. For instance, the study of two variables $(Z=2)$ will involve seven experiments. These experimental points are the labeled points 1, 2, 5, 8, 9, 11 , and 13 allocated at the center and at the vertexes of the hexagonal shape in Figure 1a.

- The selected variables are studied at different numbers of levels. Figure 1 shows how the factors $z_{1}, z_{2}$, and $z_{3}$ are studied at 5, 3, and 7 levels respectively. This characteristic is relevant when a new instrumental situation arises. For instance the temperature in a particular instrument cannot be studied at 7 levels as was planned but at the 3 levels preset by the manufacturer.

The three variables described at the beginning of this section will require a minimum of 13 experiments $\left(3^{2}+\right.$ $3+1)$ to model their effect on the selected response. The generation and distribution of these 13 experimental points is displayed in Figure $1 \mathrm{~b}$ and the coded and natural levels involved in the experimentation are given in Figure 1c. A brief explanation of these levels is as follows: the five coded levels $(-1,-0.5,0,0.5$, and 1$)$ for variable $z_{1}$ represent five different nebulizer pressures $\left(30,40,50,60\right.$, and 70 psi), for variable $z_{2}$ the three coded levels $-0.82,0$, and 0.82 represent three different drying gas flows $(8.4,10$, and $11.6 \mathrm{l} / \mathrm{min})$, and for variable $z_{3}$ the seven coded levels $-0.87,-0.58,-0.29,0,0.29,0.58$, and 0.87 represent seven different chromatographic flow rates $(0.25,0.37,0.48,0.6,0.72,0.83$, and $0.95 \mathrm{ml} / \mathrm{min})$.

The aforementioned parameters were analyzed by keeping constant the drying gas temperature at $350{ }^{\circ} \mathrm{C}$. This particular temperature was selected based on a preliminary investigation in our laboratory aiming at studying the behavior of TAG, DAG, and MAG analytical signals at different drying gas temperatures (250$\left.365^{\circ} \mathrm{C}\right)$. It was found, in all the instances, that the best analytical sensitivity is achieved at $350{ }^{\circ} \mathrm{C}$. Temperature values above $350{ }^{\circ} \mathrm{C}$ did not yield further significant increase of the signals.

Linear calibration design. The description of the linear calibration design studied in this work and represented in Figure 2 is as follows: calibration experiments were carried out at five different concentration levels $(I=5)$ in order to evaluate the relationship between the TALG concentration and its $\left[\mathrm{M}+\mathrm{NH}_{4}\right]^{+}$signal at $890.6 \mathrm{~m} / z$. The solution preparation error was evaluated by per- 
a)

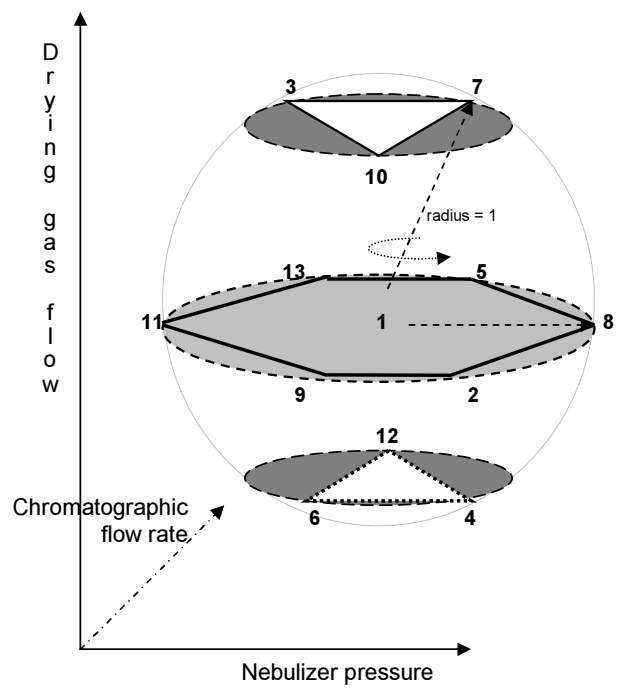

b)

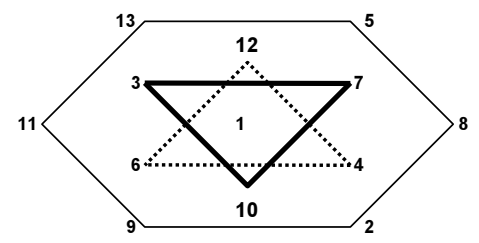

c)
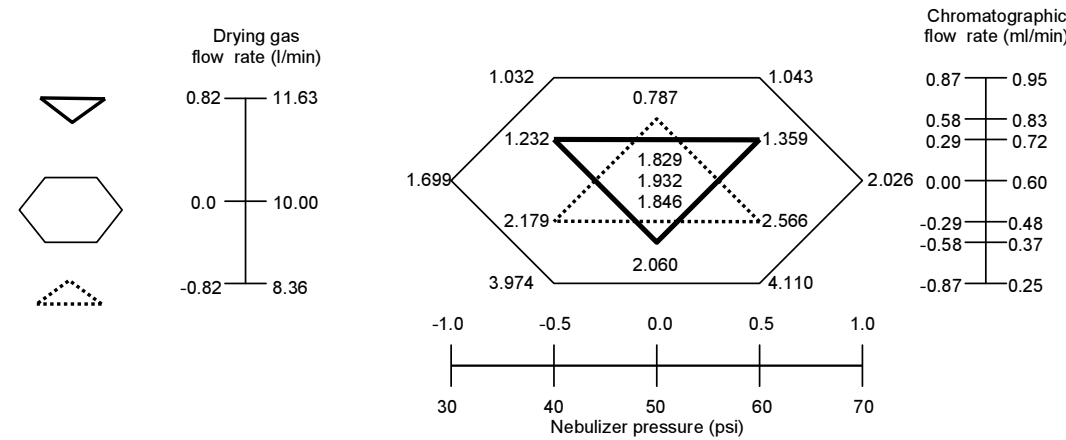

Figure 1. (a) Generation of a Doehlert matrix for two and three variables; (b) distribution of the experimental points studied in this work; (c) experimental $\left[\mathrm{M}+\mathrm{NH}_{4}\right]^{+}$area in icps $\times 10^{8}$ measured at each experimental point. Two scales are shown which correspond to the coded and natural levels of the variables.

forming $J_{i}$ independent standard solution replicates at each $i$ measurement level. The standard solution replicate $j_{i}$ is taken and $K_{i j}$ instrumental replicates are performed on it. A total of 18 measurements were performed in order to obtain the linear relationship with two parameters in the model. According to the

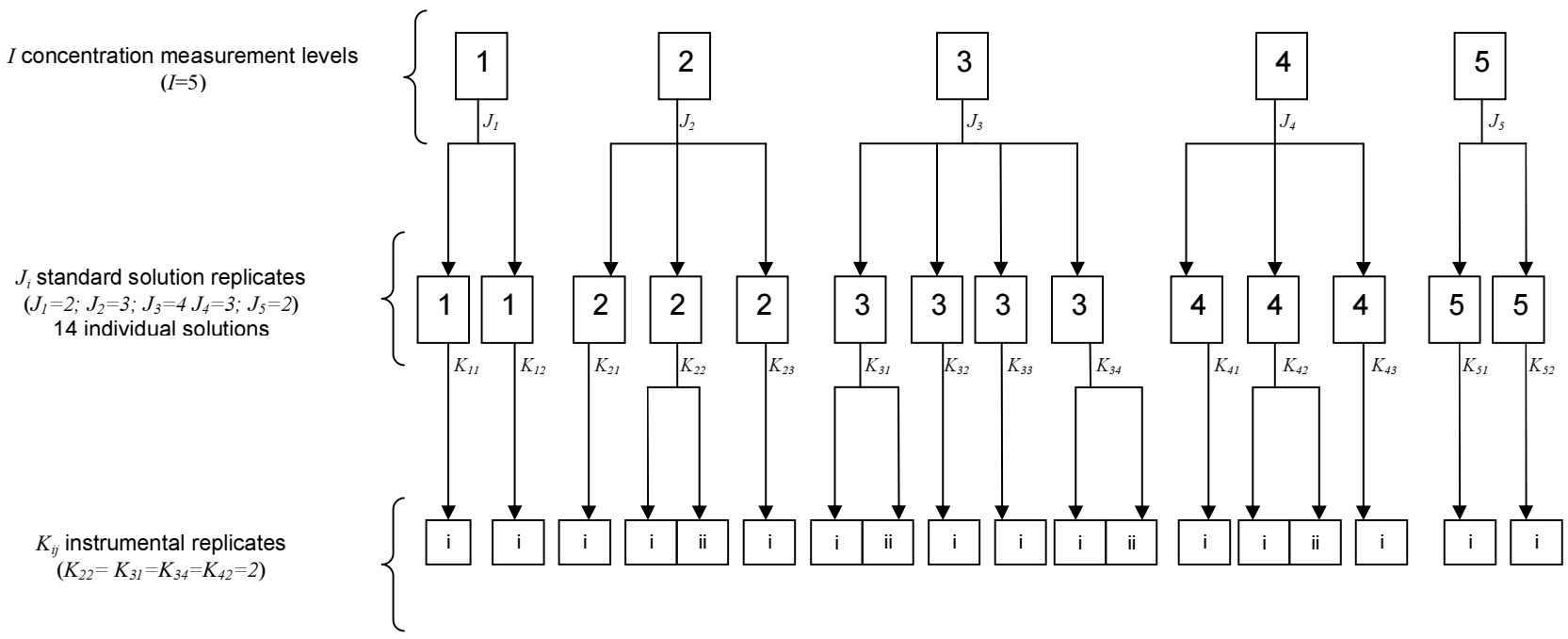

Figure 2. Experimental arrangement of the dilution and instrumental replicates evaluated in this paper. 
notation described above, a measurement at the concentration level $i$, sample replicate $j$, and instrumental replicate $k$ is recorded as $y_{i j k}$.

Standard solution replicates. The influence of the experimental errors due to inaccuracies in calibrating pipettes, mixing of solutions, evaporation, etc, described in the literature as preparation error, was assessed by making replicate solutions of the measurement levels. These measurement levels (I) showed in Figure 2, were coded from 1 (lowest concentration) to 5 (highest concentration). Levels 1 and 5 (10 and $50 \mu \mathrm{g} / \mathrm{ml}$ TALG, respectively) were replicated twice, levels 2 and 4 (20 and $40 \mu \mathrm{g} / \mathrm{ml}$ TALG, respectively) were replicated three times and level 3 (30 $\mu \mathrm{g} / \mathrm{ml}$ TALG) was replicated four times, resulting in 14 individual solutions (Figure 2).

Instrumental replicates. Instrumental noise, baseline problems, spray fluctuation, etc., may lead to different results between replicates. This particular source of error is estimated by measuring some concentration levels more than once. Instrumental accuracy becomes a problem when very low concentrations are studied. It has been proposed that for a system consisting of five measurement levels, a sensible number of degrees of freedom to estimate the instrumental error is four [13]. Based on this observation, one of the individual solutions at level 2 and level 4 and two of the individual solutions at level 3 were instrumentally replicated as is depicted in Figure 2.

Error decomposition approaches. The mean square errors associated with the instrumental $\left(S_{\text {inst }}^{2}\right)$ and the standard solution $\left(S_{\text {std }}^{2}\right)$ replicates were calculated by

$$
S_{\mathrm{inst}}^{2}=\frac{\sum_{i=1}^{I} \sum_{j=1}^{J_{i}} \sum_{k=1}^{K_{i j}}\left(y_{i j k}-\bar{y}_{i j}\right)^{2}}{\left[\sum_{i=1}^{I} \sum_{j=1}^{J_{i}} \sum_{k=1}^{K_{i j}}\left(K_{i j}-1\right)\right]}
$$

and

$$
S_{\text {std }}^{2}=\frac{\sum_{i=1}^{I} \sum_{j=1}^{J_{i}} K_{i j}\left(\bar{y}_{i j}-\overline{\bar{y}}_{i}\right)^{2}}{\sum_{i=1}^{I}\left[\left(J_{i}-1\right) \times \sum_{j=1}^{J_{i}} \frac{K_{i j}}{J_{i}}\right]}
$$

where the numerators of eqs 1 and 2 represent the sum of square errors for instrumental $\left(S S_{\text {inst }}\right)$ and standard $\left(S S_{\text {std }}\right)$ solution replicates and the mean values represent the instrumental average at each standard level $\left(\bar{y}_{i j}\right)$ and the dilution weighted average at each measurement level $\left(\overline{\boldsymbol{y}}_{i}\right)$ calculated by

$$
\bar{y}_{i j}=\frac{\sum_{k=1}^{K_{i j}} y_{i j k}}{K_{i j}}
$$

and

$$
\overline{\boldsymbol{y}}_{i}=\frac{\sum_{j=1}^{J_{i}} K_{i j} \bar{y}_{\mathrm{ij}}}{\sum_{\mathrm{j}=1}^{J_{i}} K_{i j}}
$$

The unequal number of standard solution and instrumental replicates has a direct consequence on the degrees of freedom involved in the calculation of the mean square standard solution error $\left(S_{\text {std }}^{2}\right)$ in eq 2. To recapitulate briefly, each solution at level 1 was measured once giving an average of 1 measurement/level-1. At level 2, where three solutions were prepared, two solutions were measured once and one solution was measured twice giving a total of 4 measurements and an average of 1.33 measurements/level-2 (4 measurements divided by 3 solutions). Similarly, at level 3, where four solutions were prepared, a total of six measurements were performed giving an average of 1.5 measurements/ level-3. Hence, the sum of square errors for standard solution replicates is divided by 11.83 .

$$
\begin{aligned}
& \sum_{i=1}^{I}\left[\left(J_{i}-1\right) \times \sum_{j=1}^{J_{i}} \frac{K_{i j}}{J_{i}}\right]= \\
& 1 \times\left(\frac{1}{2}+\frac{1}{2}\right)+2 \times\left(\frac{1}{3}+\frac{2}{3}+\frac{1}{3}\right)+ \\
& 3 \times\left(\frac{1}{4}+\frac{2}{4}+\frac{2}{4}+\frac{1}{4}\right)+ \\
& 2 \times\left(\frac{1}{3}+\frac{2}{3}+\frac{1}{3}\right)+1 \times\left(\frac{1}{2}+\frac{1}{2}\right)=11.83
\end{aligned}
$$

Calibration function. The linearity of a calibration function is described by

$$
\hat{y}=\alpha x_{i}+\beta
$$

where $\hat{y}$ represents the estimated intensity in ion counts per second (icps) of the $\left[\mathrm{M}+\mathrm{NH}_{4}\right]^{+} 890.6 \mathrm{~m} / z, x_{i}$ the TALG concentration in $\mu \mathrm{g} / \mathrm{ml}$ at level $i$, and $\alpha$ and $\beta$ the sensitivity of the analysis and the intercept, respectively. The linearity of the calibration function was investigated at the TALG concentration levels described above $(10,20,30,40$, and $50 \mu \mathrm{g} / \mathrm{ml})$.

The adequacy of the model is tested by calculating the F-test and comparing with the tabulated 95\% confidence level 


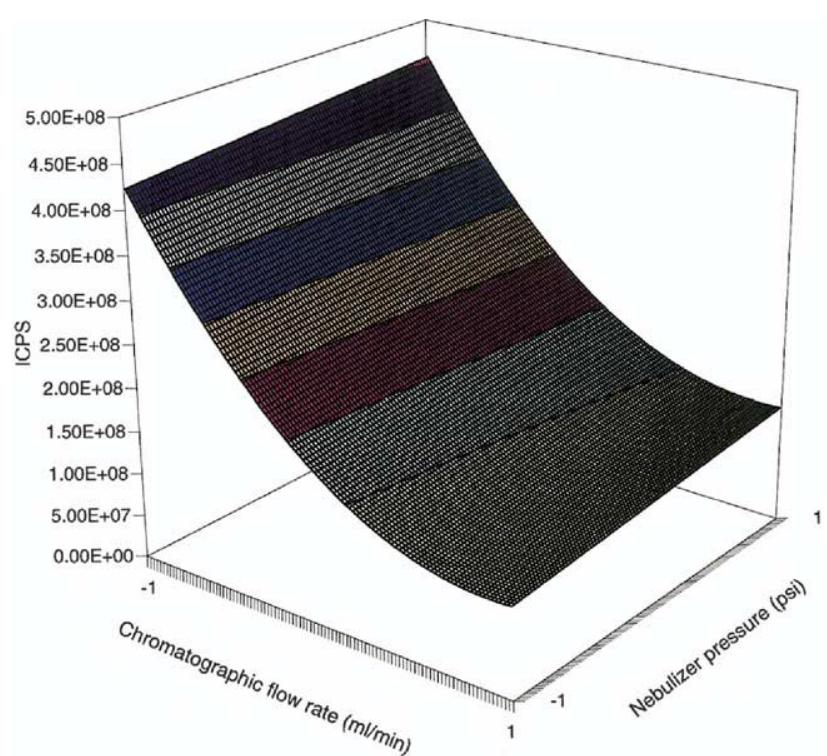

Figure 3. Response surface for nebulizer pressure and chromatographic flow rate at a drying gas flow of $10 \mathrm{l} / \mathrm{min}$.

$$
F_{\text {calculated }}=\frac{\left[\frac{S S_{\text {lof }}}{D F_{\text {lof }}}\right]}{\left[\frac{S S_{\varepsilon}}{D F_{\varepsilon}}\right]}=\frac{S_{\text {lof }}^{2}}{S_{\varepsilon}^{2}}
$$

where $S S_{\text {lof }}$ and $S S_{\varepsilon}$ represent the lack-of-fit and the pure error sum of squares error, respectively, $D F_{\text {lof }}$ and $D F_{\varepsilon}$ the associated degrees of freedom, and $S_{\text {lof }}^{2}$ and $S_{\varepsilon}^{2}$ the mean square error respectively.

$S S_{\text {lof }}$ is calculated by the difference

$$
S S_{l o f}=S S_{r}-S S_{\varepsilon}
$$

where $S S_{r}$ represents the residual sum of square error calculated by

$$
S S_{r}=\sum_{i=1}^{I} \sum_{j=1}^{J_{i}} \sum_{k=1}^{K_{i j}}\left(y_{i j k}-\hat{y}_{\mathrm{i}}\right)^{2}
$$

and

$$
S S_{\varepsilon}=\sum_{i=1}^{I} \sum_{j=1}^{J_{i}} \sum_{k=1}^{K_{i j}}\left(y_{i j k}-\overline{\bar{y}}_{i}\right)^{2}
$$

It is important to mention that the lack-of-fit should be small in respect to the residual error if a genuine linear relationship is obeyed.

The residual $\left(S_{\mathrm{r}}^{2}\right)$ and pure error $\left(S_{\varepsilon}^{2}\right)$ mean square error are calculated by

$$
S_{r}^{2}=\frac{S S_{r}}{\left(\sum_{i=1}^{I} \sum_{j=1}^{J_{i}} \sum_{k=1}^{K_{i j}} K_{i j}\right)-p}
$$

and

$$
S_{\varepsilon}^{2}=\frac{S S_{\varepsilon}}{\sum_{i=1}^{I}\left(J_{i}-1\right)}
$$

where the denominators in eqs 10 and 11 represent the degrees of freedom (16 and 9 for residual and pure error, respectively) and their difference $(16-9=7)$ denotes the degrees of freedom associated to the lackof-fit error. The term $p$ in eq 10 represents the number of parameters in the model. In the determination of the degrees of freedom associated to the pure error $\left(D F_{\varepsilon}=\right.$ 9) used in the calibration linearity testing, the approach suggested by the Analytical Methods Committee of the Royal Society of Chemistry [14] was employed, that is averaging the replicate instrumental responses at each concentration level. Finally, the adequacy of the model is tested by calculating the F-test and comparing with the tabulated $95 \%$ confidence level $\left(F_{7 / 9}=3.293\right)$.

\section{Results and Discussion}

\section{Modelling of the LCITMS Variables and Estimation of Their Optimal Combination}

Figure 1c shows the experimental results obtained after applying the uniform shell design. A total of 15 experiments were run in random order. The center of the design was replicated three times to provide sufficient degrees of freedom for the calculation of the pure error sum square.

In order to determine the behavior of the three variables studied, a full second-order polynomial model consisting of 10 parameters ( 1 intercept, 3 linear, 3 squared, and 3 interaction terms) was considered initially but after checking the significance of the 10 parameters ( $F$-test $95 \%$ confidence level) it was possible to simplify it to a reduced model that explains a

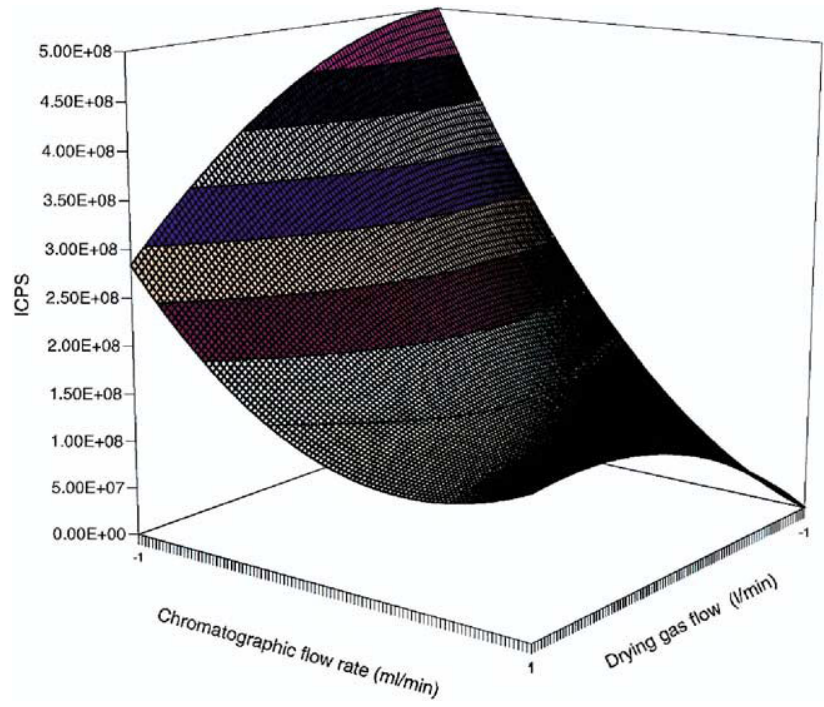

Figure 4. Response surface for drying gas flow and chromatographic flow rate at a nebulizer pressure of 50 psi. 
considerable percentage of the variability of the analytical signal $\left(r^{2}=0.99\right)$. The reduced model is described by the following equation:

$$
\begin{aligned}
& \hat{y}=1.9 \times 10^{8}+1.6 \times 10^{7} z_{1}-1.8 \times 10^{7} z_{2}-1.6 \times 10^{8} z_{3} \\
& -4.8 \times 10^{7} z_{2}^{2}+9.0 \times 10^{7} z_{3}^{2}+9.0 \times 10^{7} z_{2} z_{3}
\end{aligned}
$$

where $\hat{y}$ represents the estimated $\left[\mathrm{M}+\mathrm{NH}_{4}\right]^{+}$signal at $m / z$ 890.6, and the terms $z_{1}, z_{2}$, and $z_{3}$ represent the nebulizer pressure, the drying gas flow, and the chromatographic flow rate in coded levels, respectively. According to the reduced model, the interaction nebulizer-chromatographic flow rate $\left(z_{1} z_{3}\right)$ which has been reported to have some influence on the analytical response [15] was not significant at the 95\% confident level in the experimental range studied in this work. The reduced model also shows the significance of the interaction drying gas flow-chromatographic flow rate $\left(z_{2} z_{3}\right)$ which is generally overlooked in optimization works.
The multilinear equation given above is used to generate the response surfaces of the estimated response $\hat{y}$ against the variables. The behavior of the $[\mathrm{M}+$ $\left.\mathrm{NH}_{4}\right]^{+}$signal as a function of the nebulizer pressure and the chromatographic flow rate (Figure 3) and the nebulizer pressure and the drying gas flow (not shown) give evidence that at constant levels of either the drying gas flow or the chromatographic flow rate, variations of the nebulizer pressure do not affect the magnitude of the analytical signal. When a constant nebulizer pressure is set and the chromatographic flow rate is increased (Figure 3) the signal decreases rapidly; however between 0.8 and $1 \mathrm{ml} / \mathrm{min}$ ( 0.5 and 1 in coded levels) the signal changes slightly with the chromatographic flow rate. Figure 4 represents the behavior of the analytical signal as a function of the drying gas flow and the chromatographic flow rate. It can be seen from this figure that when the chromatographic flow rate is kept constant at $1 \mathrm{ml} / \mathrm{min}$ (coded level 1), an increase in the drying gas flow produces an enhancement on the
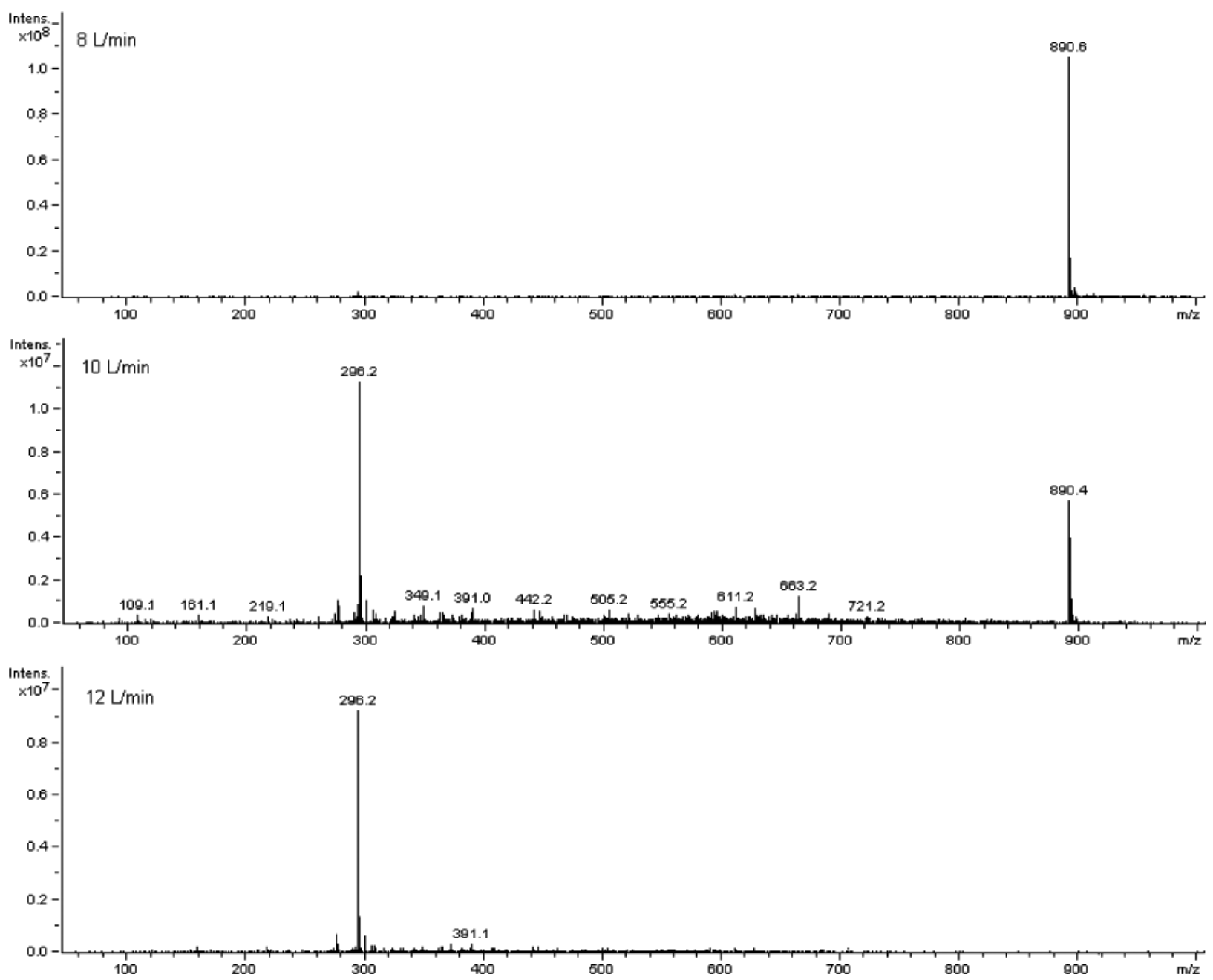

Figure 5. The effect of increasing the drying gas flow on the tri- $\alpha$-linolenoylglycerol ammoniated adduct signal $\mathrm{m} / \mathrm{z}$ 890.6. The nebulizer pressure, drying gas temperature and infusion speed were kept constant at $50 \mathrm{psi}, 350^{\circ} \mathrm{C}$ and $10 \mu \mathrm{l} / \mathrm{min}$ respectively. 
Table 1. Results of the tri- $\alpha$-linolenoylglycerol LCITMS calibration experiments

\begin{tabular}{|c|c|c|c|c|c|c|c|}
\hline $\begin{array}{l}\text { Measurement } \\
\text { level }(\mu \mathrm{g} / \mathrm{ml})\end{array}$ & $\begin{array}{c}\text { Coded } \\
\text { measurement } \\
\text { level }(I)\end{array}$ & $\begin{array}{l}\text { Standard } \\
\text { solution } \\
\text { replication }\left(J_{i}\right) \\
\end{array}$ & $\begin{array}{c}\text { Instrumental } \\
\text { replication } \\
\left(K_{i j}\right) \\
\end{array}$ & $\begin{array}{c}\text { Experimental } \\
\text { response } \\
\left(y_{i j k}\right) \\
\end{array}$ & $\begin{array}{l}\text { Instrumental } \\
\text { average } \\
\text { response } \\
\left(y_{i j}\right) \\
\end{array}$ & $\begin{array}{c}\text { Standard solution } \\
\text { weighted average } \\
\text { response }\left(\overline{\bar{y}}_{i}\right)\end{array}$ & $\begin{array}{c}\text { Estimated } \\
\text { response } \\
\left(\hat{y}_{\mathrm{i}}\right)\end{array}$ \\
\hline \multirow[t]{2}{*}{10} & 1 & 2 & 1 & 1.19 & 1.19 & 0.90 & 0.73 \\
\hline & & & 1 & 0.61 & 0.61 & & \\
\hline \multirow[t]{4}{*}{20} & 2 & 3 & 1 & 1.45 & 1.45 & 1.43 & 1.42 \\
\hline & & & 2 & 1.44 & 1.40 & & \\
\hline & & & & 1.36 & & & \\
\hline & & & 1 & 1.46 & 1.46 & & \\
\hline \multirow[t]{6}{*}{30} & 3 & 4 & 2 & 1.99 & 2.00 & 1.95 & 2.11 \\
\hline & & & & 2.00 & & & \\
\hline & & & 1 & 1.91 & 1.91 & & \\
\hline & & & 1 & 2.00 & 2.00 & & \\
\hline & & & 2 & 1.96 & 1.91 & & \\
\hline & & & & 1.87 & & & \\
\hline \multirow[t]{4}{*}{40} & 4 & 3 & 1 & 2.93 & 2.93 & 2.93 & 2.81 \\
\hline & & & 2 & 2.84 & 2.86 & & \\
\hline & & & & 2.88 & & & \\
\hline & & & 1 & 3.07 & 3.07 & & \\
\hline \multirow[t]{2}{*}{50} & 5 & 2 & 1 & 3.59 & 3.59 & 3.56 & 3.50 \\
\hline & & & 1 & 3.53 & 3.53 & & \\
\hline
\end{tabular}

All the responses in icps $\times 10^{9}$ units.

analytical signal; however there is a region around 8 and $10 \mathrm{l} / \mathrm{min}$ of drying gas flow in which the signal is almost constant. In contrast to this result, Figure 4 shows that keeping constant the chromatographic flow rate at $0.2 \mathrm{ml} / \mathrm{min}$ (coded level 1) the signal decreases when the drying gas flow rate is increased. A remarkable enhancement of the $890.6 \mathrm{~m} / \mathrm{z}$ signal is achieved when the levels of the nitrogen drying gas flow and the chromatographic flow rate are kept in the lowest magnitudes used in this work, $81 / \mathrm{min}$ and $0.2 \mathrm{ml} / \mathrm{min}$, respectively. This result was contrary to our expectations, due to the fact that the main role of the drying gas flow is to evaporate solvents in the spray chamber without decomposing the analytes thermally [15]. Further investigation aiming at studying the effect of the drying gas on the analytical signal, in order to clarify the divergence between the aforesaid reported observation and our experimental results, was carried out by infusing a sample of TALG and changing the levels of the counter-current drying gas flow between 8-12 $1 / \mathrm{min}$. The results obtained (Figure 5) suggest that the main process involved at $81 / \mathrm{min}$ is the reduction of the kinetic energy of the ions formed from charged droplets by collision with molecules of the drying gas leading to the formation of intact $\left[\mathrm{M}+\mathrm{NH}_{4}\right]^{+}$. Based on the behavior of the system at $101 / \mathrm{min}$, it is highly probable that the increase in drying gas flow causes an increase in pressure in the atmospheric pressure interface, which might lead the ions to undergo more collisions which results in an increase in the internal energy of a considerable fraction of the intact ions and in this way both $\alpha$-linolenic FFA $(296.2 \mathrm{~m} / \mathrm{z})$ and precursor ions $(890.4$ $\mathrm{m} / \mathrm{z}$ ) ammoniated adducts are formed. At $121 / \mathrm{min}$ the increasing of the internal energy is more dramatic and all the precursor ions are over the threshold of fragmentation; therefore, the formation of the FFA dominates. It is important to mention that fragmentation of TALG has been observed by using atmospheric pressure chemical ionization [2] and tandem sector MS [3] but in any of these works the FFA ammoniated adduct was observed. The fragmentation of TALG into FFA as a result of varying the drying gas flow in ESI-MS experiments, to our knowledge, has not been previously reported.

\section{Estimation of the Sources of Errors in ESI LC-Ion- Trap-MS Under Optimal Variable Conditions}

Based on the behavior of the analytical signal with the variables studied (Figures 3 and 4 ) the coded levels 1, -1 , and -1 for $z_{1}, z_{2}$, and $z_{3}$, respectively, which correspond to the experimental condition 70 psi for nebulizer pressure, $81 / \mathrm{min}$ for drying gas flow, and 0.2 $\mathrm{ml} / \mathrm{min}$ for chromatographic flow rate, were suggested to estimate the main errors involved in linear calibration experiments for the quantitative estimation of TALG. The results after measuring the dilution and instrumental replicates are shown in Table 1 with their respective instrumental average, dilution weighted average and estimated response.

Table 2 shows the results of the different source of errors studied in this work. Comparison between the sum square errors for instrumental and standard solution replication seems to indicate that instrumental stability is not of major concern in LCITMS calibration 
Table 2. Error terms studied in this work

\begin{tabular}{lccrc}
\hline & $\begin{array}{c}\text { Instrumental } \\
\text { replicates }\end{array}$ & $\begin{array}{c}\text { Standard solution } \\
\text { replicates }\end{array}$ & $\begin{array}{c}\text { Pure } \\
\text { Residuals }\end{array}$ & $\begin{array}{c}\text { Lack-of-fit } \\
\text { experimental }\end{array}$ \\
\hline \hline Sum of square errors (icps) & $7.74 \times 10^{15}$ & $2.02 \times 10^{17}$ & $4.98 \times 10^{17}$ & $2.23 \times 10^{17}$ \\
Degrees of freedom & 4 & 11.83 & $2.75 \times 10^{17}$ \\
Mean square errors (icps) & $1.93 \times 10^{15}$ & $1.71 \times 10^{16}$ & $3.11 \times 10^{16}$ & $2.48 \times 10^{16}$ \\
\hline
\end{tabular}

experiments compared to standard solution replication. The preparation error is 26 times larger than the instrumental error; for this reason TAG calibration experiments where the number of instrumental replicates is higher than the number of dilution replicates are not advisable and can be considered as poor calibration strategies.

\section{Tri- $\alpha$-Linolenoylglycerol ESI LC-Ion-Trap-MS Calibration Study}

The linear calibration was estimated by calculating the linear functional relationship between the analytical signal at $890.6 \mathrm{~m} / \mathrm{z}$ and the instrumental average at each dilution level. The error analysis, presented in Table 2, revealed that the ratio lack-of-fit to pure error variances $\left(F_{7 / 9}=1.586\right)$ gives evidence to support the adequacy of the model described by eq 5 . The calibration graph was linear between 10 and $50 \mu \mathrm{g} / \mathrm{ml}\left(r^{2}=0.96\right)$ and the analytical characteristics of the calibration graph determined by unweighted least-squares regression were $\hat{y}=3.20 \times 10^{7}+6.94 \times 10^{7} x_{i}$. The determination of TALG in synthetic mixtures at different analytical concentrations was successfully achieved without detrimental side effects from the matrices tested. The recoveries from synthetic mixtures spiked with TALG ranged from 94.6 to $99.4 \%$ and the detection limit corresponding to three times the standard deviation of the blank was found to be $9.5 \times 10^{-2} \mu \mathrm{g} / \mathrm{ml}$.

\section{Conclusions}

The application of an experimental design in LCITMS experiments aiming at measuring, modeling, and optimizing the different parameters involved in the analysis of TAG has resulted in a substantial reduction of time and resources. It is important to highlight how the uniform shell design used in this work has permitted to estimate the experimental response as a function of the experimental variables considered at a cost of about $14 \%$ of the full $5 \times 3 \times 7=105$ design and has proven to be a good component in high dimensional experimental work.

The described approaches have demonstrated that efficient experimentation is based on experimental design and subsequent quantitative evaluation of the relationship between factors and responses. The described uniform shell design and error decomposition approaches can be applied to the study of others parameters different from those considered in this work. The reader interested in the implementation of these or other kind of designs is referred to a series of tutorials with examples taken from the literature by Araujo and Brereton [16-18].

By applying experimental design we have demonstrated that it is possible to fragment the backbone of the tri- $\alpha$-linolenoylglycerol and obtain the free $\alpha$-linolenic fatty acid by using ESI MS alone. The application of multivariate approaches, in order to study the effect of the drying gas in combination with other MS variables such as the voltages in the electrospray source and high order MS coupled to liquid chromatography, could offer a great deal of potentialities in the structural characterization of FFA and the identification of the relative disposition of the acyl groups on the glycerol backbone. Such studies can pave the way for the development of selective TAG fragmentation methods which are essential to gain a clear understanding of the dynamic of TAG and FFA in areas such as human nutrition.

\section{References}

1. Barrett, L. W.; Sperling, L. H.; Murphy, C. J. Naturally Functionalized Triglyceride Oils in Interpenetrating Polymer Networks. J. Am. Oil. Chem. Soc. 1993, 70, 523-534.

2. Mu, H.; Sillen, H.; Høy, C. Identification of Diacylglycerols and Triacylglycerols in a Structured Lipid Sample by Atmospheric Pressure Chemical Ionization Liquid Chromatography/Mass Spectrometry. J. Am. Oil. Chem. Soc. 2000, 77, 1049-1059.

3. Cheng, C.; Gross, M. L. Complete Structural Elucidation of Triacylglycerols by Tandem Sector Mass Spectrometry. Anal. Chem. 1998, 70, 4417-4426.

4. Vance, D. E.; Vance, J. Fatty Acid Desaturation and Chain Elongation in Eukaryotes. In Biochemistry of Lipids, Lipoproteins, and Membranes; Vance, D. E.; Vance, J. E., Eds.; Elsevier: Amsterdam, 1996; p 129.

5. Terry, P.; Lichtenstein, P.; Feychting, M.; Ahlbom, A.; Wolk, A. Fatty Fish Consumption and Risk of Prostate Cancer. Lancet 2001, 357, 1764-1766.

6. Folch, J.; Lees, M.; Stanley, G. H. S. A Simple Method for the Isolation and Purification of Total Lipids from Animal Tissues. J. Biol. Chem. 1957, 226, 497-509.

7. Bligh, E. G.; Dyer, W. J. A Rapid Method of Total Lipid Extraction and Purification. Can. J. Biochem. Physiol. 1959, 37, 911-917.

8. Christie, W. W. Mass Spectrometry of Picolinyl Ester, Dimethyloxazoline and Related Derivatives. In Advances in Lipid Methodology; 4. Christie, W. W., Ed.; Oily Press: Dundee, 1997; p 137.

9. Scholz, B.; Ballschmiter, K. Preparation and Reversed-Phase High-Performance Liquid Chromatography of Chlorophylls. J. Chromatogr. A 1981, 1, 148-155. 
10. Vecka, M.; Tvrzická, E.; Staňkov, B.; Žak, A. Effect of Column and Software on Gas Chromatographic Determination of Fatty Acids. J. Chromatogr. B 2002, 770, 91-99.

11. Van Leeuwen, J. A.; Buydens, L. M. C.; Vandeginste, B. G. M.; Kateman, G.; Schoenmakers, P. J.; Mulholland, M. RES, an Expert System for the Set-Up and Interpretation of a Ruggedness Test in HPLC Method Validation: Part 1: The Ruggedness Test in HPLC Method Validation. Chemom. Intell. Lab. Syst. 1991, 10, 337-347.

12. Doehlert, D. H. Uniform Shell Designs. Appl. Stat. 1970, 19, 231-239.

13. Araujo, P.; Brereton, R. Rational Design of Linear Calibration Experiments for the Quantitative Estimation of Chlorophyll $a$
Using High-Performance Liquid Chromatography, Atomic Absorption Spectrometry, and Electronic Absorption Spectrometry. Analyst 1995, 120, 2497-2504.

14. Analytical Methods Committee. Is My Calibration Linear? Analyst 1994, 9, 2363-2366.

15. Agilent Technologies. Drying Gas. In Agilent 1100 Series LC/MS Trap Operations Manual; Version 4.2, U.S. 2002; pp 9, 162.

16. Araujo, P. W.; Brereton, R. G. Experimental Design. I. Screening. Trends Anal. Chem. 1996, 149, 26-31.

17. Araujo, P. W.; Brereton, R. G. Experimental Design. II. Optimization. Trends Anal. Chem. 1996, 150, 63-70.

18. Araujo, P. W.; Brereton, R. G. Experimental Design. III. Quantification. Trends Anal. Chem. 1996, 151, 156-163. 